\title{
Meta
}

Journal des traducteurs

Translators' Journal

\section{Concept of Constrained Translation. Non-Linguistic Perspectives of Translation}

\section{Roberto Mayoral, Dorothy Kelly et Natividad Gallardo}

Volume 33, numéro 3, septembre 1988

URI : https://id.erudit.org/iderudit/003608ar

DOI : https://doi.org/10.7202/003608ar

Aller au sommaire du numéro

Éditeur(s)

Les Presses de l'Université de Montréal

ISSN

0026-0452 (imprimé)

1492-1421 (numérique)

Découvrir la revue

Citer cet article

Mayoral, R., Kelly, D. \& Gallardo, N. (1988). Concept of Constrained Translation. Non-Linguistic Perspectives of Translation. Meta, 33(3), 356-367.

https://doi.org/10.7202/003608ar

\section{Résumé de l'article}

The procedures involved in the translation of texts have been widely studied from a linguistic point of view. However, when translation is required not only of written texts alone, but of texts in association with other communication media (image, music, oral sources, etc.), the translator's task is complicated and at the same time constrained by the latter. We introduce in this paper the concept of constrained translation from the point of view of communication theory (as defined by the terminology of Nida "dynamic translation"); we also deal with the existence of more than one communication channel, the factors of source culture, target culture, "noise", and the role of the translator in this complex process. 


\title{
CONCEPT OF CONSTRAINED TRANSLATION. NON-LINGUISTIC PERSPECTIVES OF TRANSLATION
}

\author{
ROBERTO MAYORAL, DOROTHY KELLY AND NATIVIDAD GALLARDO \\ Escuela Universitaria de Traductores e Intérpretes \\ Universidad de Granada, Espagne
}

\begin{abstract}
The procedures involved in the translation of texts have been widely studied from a linguistic point of view.

However, when translation is required not only of written texts alone, but of texts in association with other communication media (image, music, oral sources, etc.), the translator's task is complicated and at the same time constrained by the latter.

We introduce in this paper the concept of constrained translation from the point of view of communication theory (as defined by the terminology of Nida "dynamic translation") ; we also deal with the existence of more than one communication channel, the factors of source culture, target culture, "noise", and the role of the translator in this complex process.
\end{abstract}

In this paper we have tried to synthesize the work of non-linguistic aspects of translation which we have been engaged in collectively for four years.

We have studied the communication process and the task which the translator must accomplish when the text is influenced by the concurrence of other communication systems or elements such as image, music, etc.

To achieve this we have relied particularly on our teaching experience in the translation of film scripts, drama, advertisements, lyrics, comic strip dialogues, etc. We have centered essentially on :

- a description of the communication process in the translation of different types of texts, including the comparison of the signals which form part of the source language message and the target language translation,

the different "noise-producing" circumstances in this translation process,

- the concept of constrained translation, as proposed by Christopher Titford, in which the text is only one of the components of the message or when it constitutes only an intermediate stage for a speech read aloud or dramatized,

- the different degrees of constraint found in the translation of different types of messages.

Traditionally, translation has been studied as a branch of applied linguistics; from this perspective, the major problem of translation consists of finding words in a target language which render the meanings stated in the source language.

This unilateral linguistic focus prevents us from taking into account aspects of the translation process beyond this limited scope, those aspects which are characteristic of translation as a communication process and also those which depend on the relation of the linguistic message to other messages conveyed by non-linguistic systems. As early as 1964, Nida dedicated chapter six of his book Toward a Science of Translating ${ }^{2}$ to the study of translation from the perspectives of information and communication theories, 
emphasizing important concepts for the translator such as "noise", "redundancy", and "communication load", formerly defined by Shannon and Weaver in 1948 in their work The Mathematical Theory of Communication ${ }^{3}$.

We regard the basic process of translation as a communicative act as follows :

Figure 1

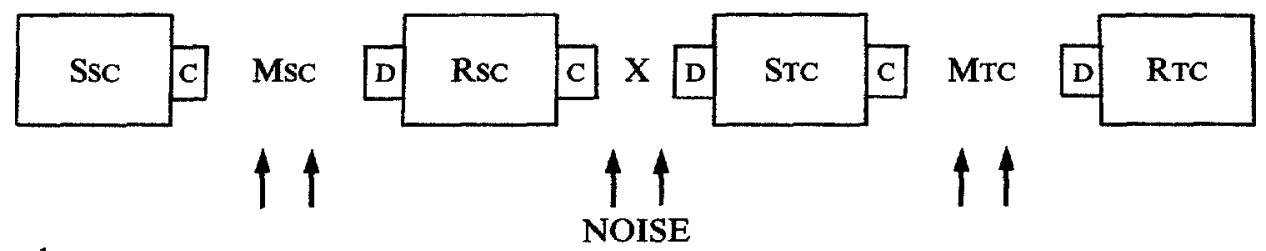

where

\section{NOISE}

$\mathrm{S}_{\mathrm{SC}}=$ source in the source culture (author)

$\mathrm{S}_{\mathrm{TC}}=$ source in the target culture (translator)

$\mathbf{R}_{\mathrm{SC}}=$ receptor in the source culture (translator)

$\mathbf{R}_{\mathrm{TC}}=$ receptor in the target culture (reader)

$\mathbf{M}_{\mathrm{SC}}=$ message coded in the source culture (text alone)

$\mathbf{M}_{\mathrm{TC}}=$ message coded in the target culture (text alone)

$\mathrm{C}=$ encoder

$\mathrm{D}=$ decoder

$\mathrm{X}=$ translation

from which we can observe that the translator acts as a decoder of the source language as well as an encoder of the target language, as a receptor of the message in the source culture as well as a source of the message in the target culture. From this point of view $\mathbf{M}_{\mathrm{SC}}$ and $\mathbf{M}_{\mathrm{TC}}$ will have to keep a "dynamic equivalence relation" according to Nida's terminology, in which the relation between the message and the response which is evoked in the receptor of each culture should be the same.

Another somewhat more complicated translation process would occur when $\mathbf{M}_{\mathrm{TC}}$ is substituted by an equivalent message in the target language which, unlike the first situation we have mentioned, does not use written language as a medium but rather oral language $\left(\mathbf{M}_{\mathbf{T C}}\right)$. The diagram would be as represented in Figure 2 :

Figure 2

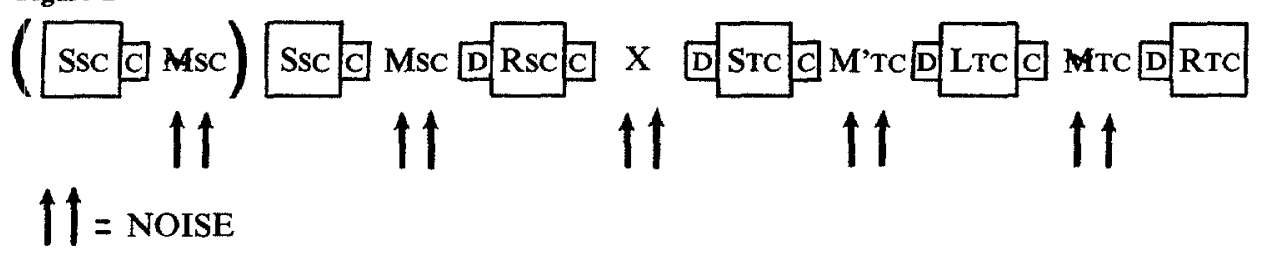

where $M^{\prime}$ TC would stand for the text to be read aloud and $L_{T C}$ would stand for the reader. Normally, $\mathbf{M}_{\mathrm{SC}}$ would only stand for the transcription of a previous message in oral form $\left(\mathrm{M}_{\mathrm{SC}}\right)$. It is relevant for the translator to know whether his translated text is going to be read aloud or silently, since the stylistic norms to be followed would be different in each case.

A further complication in the translation process occurs when the text is dramatized $\left(\mathbf{M}_{\mathbf{T C}}\right)$. The most characteristic situation is that of the theater, where we find several kinds of problems as mentioned by S.S.C. Chau ${ }^{4}$. First of all, the $\mathbf{M}_{\mathrm{SC}}$ (written) work alone fails to provide us with a true or complete vision of the original work which 
can only be fully conceived by means of the theatrical performance. But it becomes difficult to define this "original work" since each performance has its own individual characteristics, even when the author is also the director. If we set aside this preliminary process and we begin with the script, $\mathbf{M}_{\mathbf{S C}}$, the major problem is that the final form of the message in the target culture - the theatrical performance - is shaped by all members who participate in the performance, from the director to the actors who interpret the work in their own light. For this reason the number of intermediate steps from the $\mathrm{A}_{\mathrm{TC}}$ as a translated text to the performance in the target culture ${ }_{\mathrm{TC}}$ may be considerable. In a simplified form, it would be as shown in Figure 3 :

Figure 3

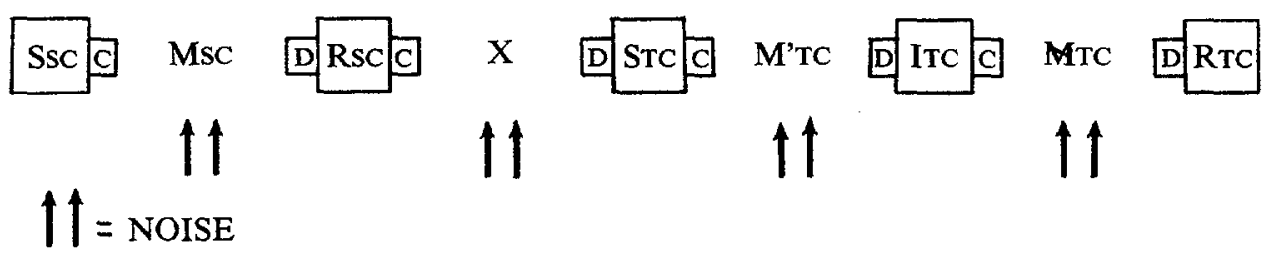

where $\mathbf{I}_{\mathrm{TC}}$ will stand for all those who intervene in the mise en scène of the translated text.

For certain types of translation, a new focus seems necessary in addition to the linguistic and communicative ones, e.g. a semiological focus which allows us to consider the message to be composed not only of the linguistic system, but also of other nonlinguistic systems which, though not specific objects of the translation process, must be considered by the translator.

The non-verbal messages will be transmitted through the visual channel (iconic signals) or through the aural channel (music, noise). Experiments have also been carried out in relation to the olfactory channel, although for the purposes of this paper we have chosen to consider only by aural and visual channels.

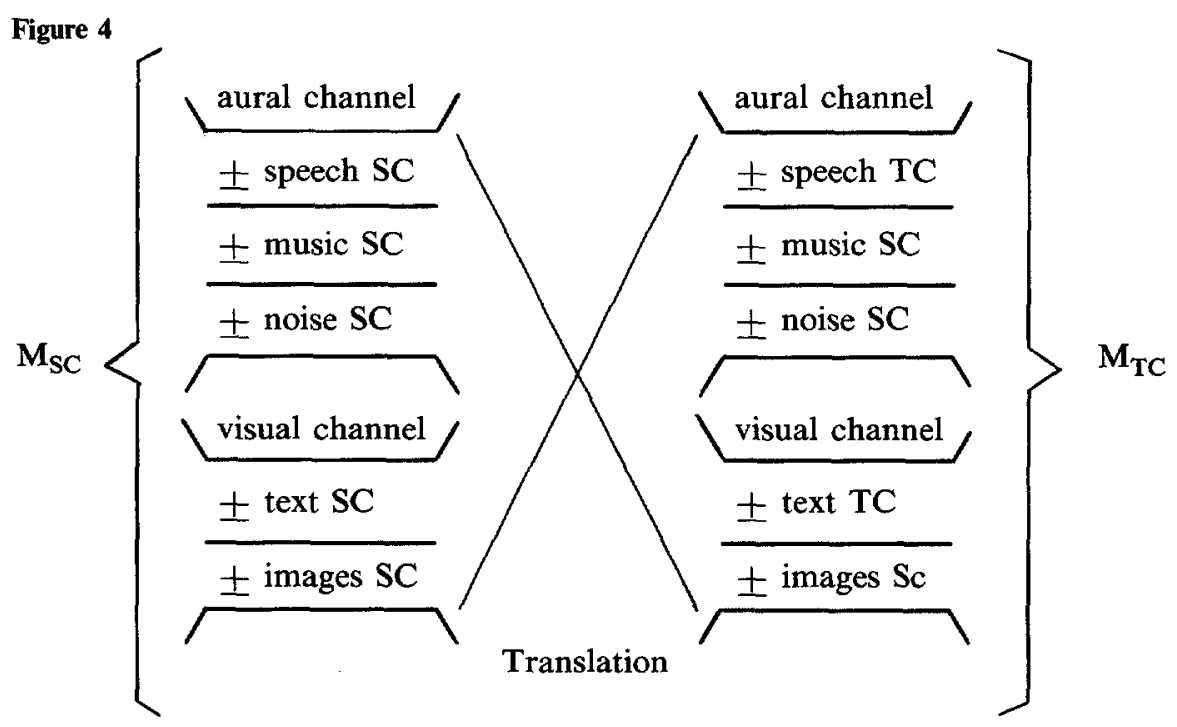


This figure shows both messages $\mathbf{M}_{\mathrm{SC}}$ and $\mathbf{M}_{\mathrm{TC}}$ with both channels functioning in an extensive range of possibilities and media. Normally, the more common combinations are as follows :

speech

text

text/images (advertisement, comic strip)

text/music (song)

speech/images (film, television)

speech/images/music/noise (film)

speech/text/images/music/noise (subtitled film)

The images will occur principally as

- an isolated image (poster)

a succession of static images (comic strip)

- a succession of images in movement (film)

The images will also reflect different degrees of "iconicity", i.e. reproduction of reality : from the drawing to the photograph, from the black and white image to the multicolored one, from the abstract to the figurative.

The media can be formed by several components. Thus, in comic strips we find narration and dialogue; in songs we have the human voice plus musical instruments and in film we can find text, image and subtitles.

Nor is the separation between the different media so precise. Iconic and conventional signs interact in a dialectical way. One of them may assume the function of the other. For example, writing - a conventional system - may possess an iconic value in a comic strip.

We must emphasize that both in the source and target culture messages, music, noise and image (which may also include text) unmistakably reveal themselves as belonging to the source culture. That is to say, the translator can only translate the text or speech (sometimes not even completely) while all the other media of the message remain untouched. This fact is a source of noise because of the bicultural nature of the message.

The relation which exists between information transmitted at a given moment through the different media and channels ranges from totally identical to totally complementary, or, in some cases, to having no relation whatsoever.

All these possibilities offer us different degrees of noise and redundancy in communication.

From the aforementioned we derive a fundamental concept involved in this type of message : synchrony ${ }^{5}$. We must understand this synchrony as the agreement between signals emitted for the purpose of communicating the same message. There are, however, various types of synchrony :

synchrony of time : agreement in time of different signals which communicate a unit of information,

spatial synchrony : the signal occupy neither more nor less space than that which corresponds to them,

content synchrony : the meanings transmitted by different signals contradict neither each other the whole message,

phonetic synchrony : synchrony of sound signals of spoken dialogue with the visible speech movements on the screen,

character synchrony : the harmony between the image of the character and his or her voice and words. 
We must emphasize the fact that different acts of communication are characterized by the relative communication importance of the different channels and media involved. For example, film relies mainly on image for its narrative capacity and dialogue plays a complementary role, whereas in drama dialogue has a greater communicative impact. Figure 5 attempts to represent both cases.

\begin{tabular}{ll} 
visual channel \\
\hline speech \\
\hline moisic \\
film (non-subtitled)
\end{tabular}

Figure 5

Relation between information transmitted by different channels for the purpose of conveying the same message

Although the channels or media may vary, we must consider the message to be a whole created as a result of the concurrence of different signals. This does not imply, however, that the sum of signals would transmit the sum of the meanings.

In communication we can receive and transmit information simultaneously through all the different sensory channels, although the most commonly used are the visual and aural.

Signals consisting of the same type of system will necessarily have to be transmitted by different channels ; such is the case of reading a text and listening to its oral translation, where the two activities can be carried out simultaneously because they do not share the same channel. Nevertheless, simultaneous interpretation, for example, shares the same channel as the original speech, making simultaneous perception of the two messages impossible and converting the original speech into "noise".

\section{Relation between information transmitted by different media}

Nevertheless, we can receive information by different media at the same time and through the same sensory channel if they are organized sufficiently in a different way, as Jeanne Martinet mentions in her book Clefs pour la sémiologie ${ }^{6}$. For example, narrative text, drawing and dialogue through the visual channel in the comic strip; subtitles and image through the visual channel and music, noise and dialogue through the aural channel in film.

\section{Translation as an intercultural process}

The different languages of $\mathbf{M}_{\mathrm{SC}}$ and $\mathbf{M}_{\mathrm{TC}}\left(\mathbf{L}_{\mathrm{SC}}\right.$ and $\left.\mathbf{L}_{\mathrm{TC}}\right)$ are nothing more than a manifestation - although the most outstanding - of the fact that the communicative act in translation occurs between two different cultures (SC and TC). This fact implies 
that the noise produced in the act of communicating by means of translation proceeds not only from the use of two different languages but also from the cultural differences existing between the source and the receptor. These differences cause a "drawing out" of the receptor channel, which in turn calls for a more explicit message or the adaptation of the message by the translator, as shown in Figure 6 .

Figure 6
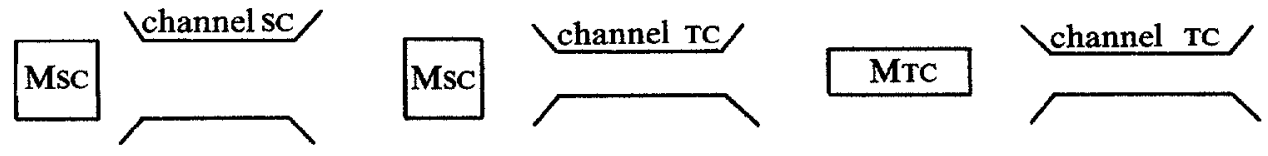

Although these procedures are carried out with relative ease in the nonconstrained or ordinary translation of a text in prose, whether literary or not, in constrained translation the translator's task is complicated by the existence of different channels and media.

\section{Noise produced by the duplication of information}

a) Information transmitted by several media through the same channel which is not organized in a sufficiently different way.

This is the case of speech SL and speech TL in Figure 7 representing $\mathbf{M}_{\mathrm{TC}}$ in onsight or simultaneous translation of films, where we observe that speech, music and noise will indeed be sufficiently organized.

The speech sounds of one dialogue will be superimposed on the other, although speech TC will not be modified.

Figure 7

\begin{tabular}{l} 
aural channel \\
\hline speech SC \\
\hline music SC \\
\hline noise SC \\
visual channel \\
image SC \\
on-sigh translation
\end{tabular}


Figure 8

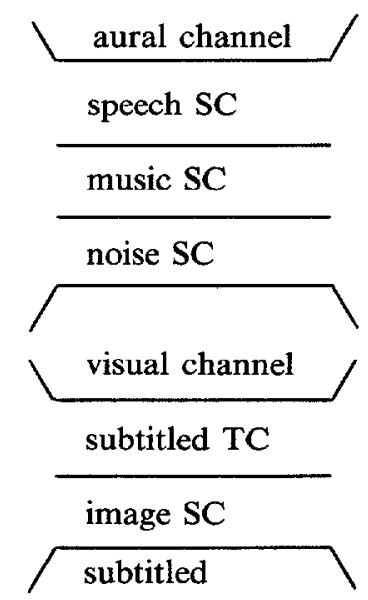

In Figure 8, which shows $M_{T C}$ for film subtitles, we notice the noise produced by the concurrence in the same channel of subtitle TC and image SC and, in addition, the subtitles superimposed in this situation produce a deformation of part of the original image, which is hidden by them. nels.

b) Information belonging to the same system but transmitted by different chan-

In Figure 8 subtitles reflect this situation of noise created by the presence of verbal signals in the aural channel in the form of speech SL and verbal signals in the visual channel in the form of subtitles TL.

Noise produced by the coexistence of different cultural systems

This is illustrated by the appearance on the screen of scenes of Moscow with actors speaking Spanish, or by the assignation in the dubbing of film of varieties of language peculiar to Spain to characters whom the image reveals as non-Spanish, as shown in Figure 9.

\section{Noise due to dischrony}

We have already referred to the different types of synchrony which may exist between different types of signals. In the event of absence of synchrony, noise is produced. For example, a subtitle which does not correspond to the image on the screen will produce noise in the decoding of the message.

\section{Constrained translation}

Unlike non-constrained translation, in which, in both SL and TL, the written language system is not accompanied by other systems and where the message occupies only the visual channel, we will find two types of circumstances which will condition our 
Figure 9

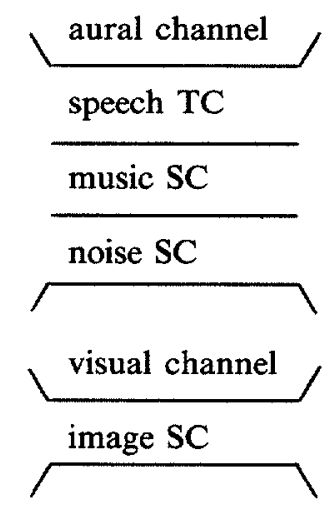

translation of the text. These circumstances will remove the condition of freedom which allows us, in isolated written prose, to approach the highest degree of dynamic equivalence in our translated text.

These two circumstances are as follows:

a) the existence of various systems of communication,

b) in some cases, the change from the visual channel for the text in the SL to the aural channel for the reading or reciting of the message in the TL (adaptation of the message to the norms of oral language).

We can also consider the limitation which poetic language imposes on translation (rhyme, metrics...), although we believe that this goes beyond the purpose of this paper.

a) Various systems of communication

When the message is composed of other systems in addition to the linguistic one, the translated text should maintain content synchrony with the other message components, whether these be image, music or any other. By this we do not suggest that the different parts of the message should mean the same thing but rather they should not contradict one another unless this has been the intention of the original; in the same way the level of redundancy for the text as a whole, as a result of adequate cultural adaptation, must allow the same facility of decoding as for the message in the SL.

On the one hand, we cannot translate the text without understanding how the other communicative elements add to or modify the meaning; and, on the other hand, the non-linguistic elements of the message not only constitute part of the meaning but also, on occasions, impose their own laws and conditions on the text. If the text does not adjust to these conditions it will not fulfill its communicative function in the whole nor will it allow the other systems to do so. We must remember that, as previously indicated, the translator can only work with the text and all the necessary adjustments must be made in relation to the text.

In the second place, the non-linguistic systems of communication and the text must fulfill the conditions of synchrony as described. If our text goes beyond the different limits imposed by the conditions of synchrony, extreme "noise" may be produced which may cause either a failure in the communication act or, at the very least, additional difficulty in the act of decoding. 
b) Change from the text through the visual channel to speech through the aural channel

The norms of oral language impose a new limitation on the translated text which will be removed from its natural environment, the printed word. This will be the case with all texts whose final destiny is that of being read aloud, recited, or sung.

If we assign degrees of constraint to different types of communication acts depending on their non-compliance with the conditions of what we have called nonconstrained translation, we can establish the range as shown in the following table.

This table is quite simplified, although the themes involved have been studied by us in greater depth in various articles ${ }^{7}$. We should not mistake the evaluation of the difficulty of the translation of the text, although these may on occasion be related.

Table 1 : Degrees of Constraint

\begin{tabular}{|c|c|c|c|c|c|c|c|}
\hline & Conter & nchrony & Spatial & Synchrony & Phonetic & Spoken & Degree of \\
\hline & Music & Image & synchrony & of time & synchrony & language & constraint \\
\hline Prose & - & - & - & - & - & - & 0 \\
\hline & & ingle/stat & & & & & \\
\hline Advertisement & - & $(\mathrm{X})$ & $\mathbf{X}$ & - & - & - & $1-2$ \\
\hline & & eries/stati & & & & & \\
\hline Comic & - & $\mathrm{X}$ & $\mathrm{X}$ & 一 & - & - & 2 \\
\hline Song & $\mathrm{X}$ & - & $X$ & $\mathrm{x}$ & - & $x$ & 4 \\
\hline Subtitles & $(\mathrm{X})$ & $\begin{array}{l}\text { Series/ } \\
\text { dynamic } \\
\text { X }\end{array}$ & $\mathrm{X}$ & $\mathrm{x}$ & - & - & $3-4$ \\
\hline & & $\begin{array}{c}\text { Series/ } \\
\text { dynamic }\end{array}$ & & & & & \\
\hline Dubbing & $(X)$ & $\mathrm{X}$ & - & $X$ & $\mathrm{X}$ & $\mathrm{X}$ & $4-5$ \\
\hline
\end{tabular}


Different types of constrained translation processes

TEXT

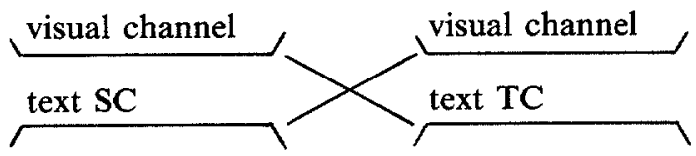

$\mathrm{M}_{\mathrm{SC}} \quad \mathbf{M}_{\mathrm{TC}}$

ADVERTISEMENT

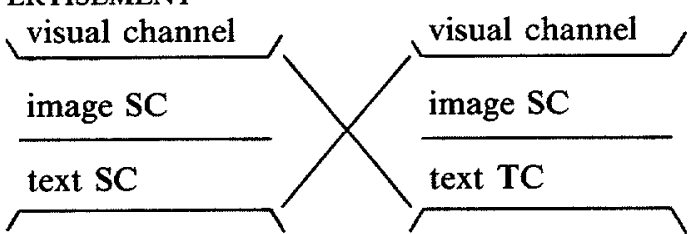

$\mathrm{M}_{\mathrm{SC}} \quad \mathbf{M}_{\mathrm{TC}}$

COMIC

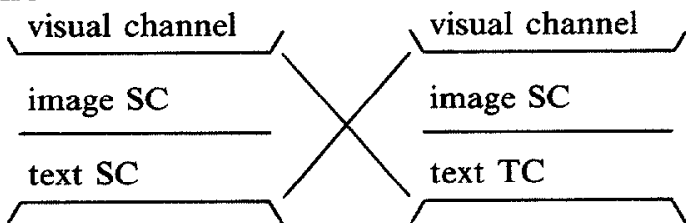

$\mathbf{M}_{\text {SC }} \quad \mathbf{M}_{\mathbf{T C}}$

SONG

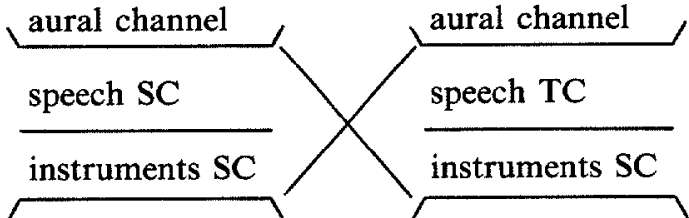

$\mathbf{M}_{\mathrm{SC}} \mathbf{M}_{\mathrm{SC}} \mathbf{M}_{\mathrm{TC}} \mathbf{M}_{\mathrm{TC}}$

DUBBING

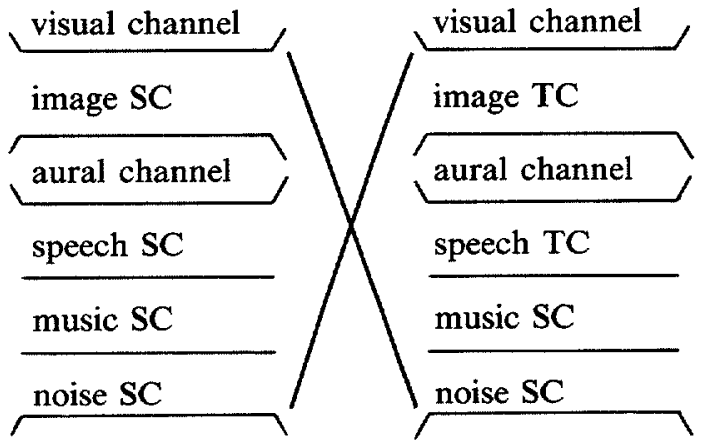

$$
\mathbf{M}_{\mathrm{SC}} \mathbf{M}_{\mathrm{SC}} \mathbf{M}_{\text {TC }} \mathbf{M}_{\mathrm{TC}}
$$

The original dramatic interpretation of the text is lost. 


\section{SIMULTANEOUS INTERPRETATION OF FILMS}

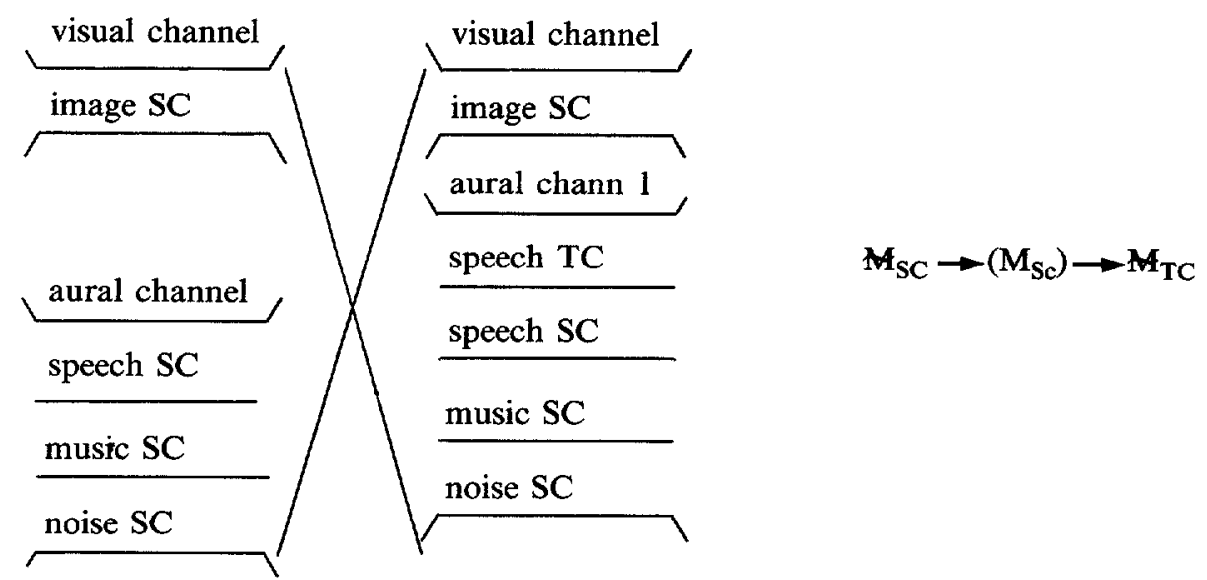

All dramatic effect is lost and character dischrony is produced.

\section{SUBTITLES}

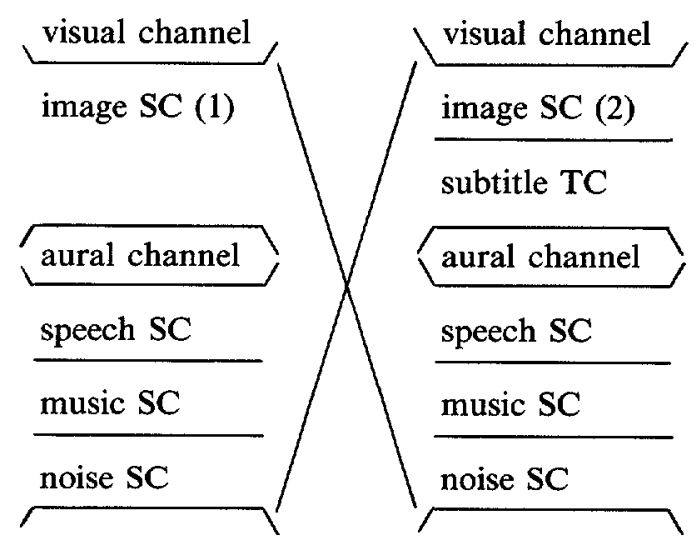

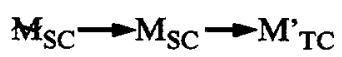

Subtitles do not have dramatization. Due to the shift from the oral word to the written text ( $\mathbf{A}_{\mathrm{SC}}$ to $\mathrm{M}_{\mathrm{TC}}$ ) a good deal of the active function of the spectator for the encoding of a parallel message is lost (see Nida, op. cit., p. 123).

Image SC (1) changes to image SC (2) because of the addition of superimposed subtitles.

Notes

1. Titford, Christopher (1982) : "Sub-titling-Constrained Translation", in Lebende Sprachen, III, pp. 113-116.

2. Nida, Eugene A. (1964) : Toward a Science of Translating, Leiden, E.J. Brill.

3. Shannon and Weaver (1948): The Mathematical Theory of Communication, Urbana, University of Illinois.

4. Chau, S.S.C. (1983): "The Nature and Limitations of Shakespeare Translation", in The Incorporated Linguist, vol. 22, $\mathrm{n}^{\circ} 1$, Winter, pp. 16-21. 
5. Fodor, Istvan (1976) : Film Dubbing : Phonetic, Semiotic, Esthetic and Psychological Aspects, Hamburg, Buske.

6. Martinet, Jeanne (1973) : Clefs pour la sémiologie, Paris, Seghers.

7. Kelly, D. and R. Mayoral (1984) : "Notes sobre la traducción de cómics", no 1, January, Granada, pp. 92-101.

Kelly, Dorothy (1984) : "Asterix in Translation", in Babel : revista de los estudiantes de la EUTI, $\mathrm{n}^{\circ} 1$, January, pp. 1-14.

Mayoral, Roberto (1984) : "El doblaje de películas y la fonética visual" in Babel : revista de los estudiantes de la EUTI, $\mathrm{n}^{\circ} 2$, May, pp. 7-15. "La traducción y el cine : el subtitulado", in Babel : revista de los estudiantes de la EUTI, $\mathrm{n}^{\circ}$ 2, May, pp. 16-26. "Los cómics : de la reproducción gráfica de sonidos a los verbos dibujados en inglés. Más sobre problemas de traducción", in Babel : revista de los estudiantes de la EUTI, $\mathrm{n}^{\circ}$ 2, May, pp. $120-130$. 